\title{
How Culture Might Impact on the Implementation of Enterprise Resource Planning Packages
}

\author{
Marina Krumbholz and Neil Arthur McDougall Maiden \\ Centre for Human-Computer Interaction Design \\ City University \\ Northampton Square, London, EC1V OHB \\ Tel: +44-171-477-8412 \\ Fax: +44-171-477-8859 \\ M.Krumbholz@city.ac.uk
}

\begin{abstract}
ERP (Enterprise Resource Planning) packages provide generic offthe-shelf business and software solutions to customers. However, these are implemented in companies with different corporate and national cultures, and there is growing evidence that failure to adapt ERP packages to fit these cultures leads to projects which are expensive and overdue. This paper describes research which synthesises social science theories of culture to be able to model and predict the impact of culture on ERP package implementation. It describes a knowledge meta-schema for modelling the surface and the deeper manifestations of culture, and for integrating these models with more common business concepts such as processes, events and information flows. It reports data from an analysis of a recent ERP implementation in a higher education institution to validate the knowledge meta-schema. It concludes with an outline of a method for ERP implementation to ensure a fit with the customer's corporate and national culture.
\end{abstract}

\section{The Impact of Culture on ERP Implementation}

ERP (Enterprise Resource Planning) software packages are an essential part of enterprise-wide information systems. An ERP package, such as SAP's R/3, is a large off-the-shelf software solution which provides integrated business and software systems to a customer. Unlike the traditional software development approach, which promotes building systems from scratch, ERP packages encapsulate reusable best business processes and software. Customers purchase the package then configure its business processes and software systems to meet their requirements. At the end of 1997, Business Week estimated the value of the ERP market at \$10 UK billion and growing. Indeed, ERP packages are a significant part of a total software package market set to surge ahead with total licence revenues growing from $\$ 8.5 \mathrm{UK}$ bn worldwide in 1998 to $\$ 20.8 \mathrm{UK}$ bn in 2003, and predictions that over $60 \%$ of Europe's business solutions will be developed from packages by 2003 (source: Forrester research). 
However, a recent Standish Group report on ERP implementation projects reveals that these projects were, on average, $178 \%$ over budget, took 2.5 times as long as intended and delivered only $30 \%$ of promised benefit. A survey of 12 recent projects revealed that adapting the implementation to the prevailing cultural style was one important cause of this project under-performance [7]. This importance of culture is hardly surprising. A customer who implements an ERP package has to change its business processes to the ERP supplier's best-practice processes [4]. The change both impacts on the customer's corporate culture (i.e. the ways that things are done in the organisation) and is constrained by it. In Europe, the picture is even more complex because companies also have diverse national cultures which influence this corporate culture and make the successful implementation of multi-national ERP solutions difficult. A recent such ERP implementation encountered major problems due to differences between the different participating national partners [10]. Indeed, evidence suggests that ERP implementations in North America have been more effective because of the more complex European corporate and national cultures [22]. If more ERP implementations are to deliver their promised benefits within budget, we need to understand how corporate and national culture impact on ERP implementations, and how this understanding will deliver better methods for implementation partners and customers to use.

In contrast to the lack of research in computer science, social and system science has researched the influence of corporate and national culture on organisational behaviour. Unfortunately this research neither addresses issues which are specific to information systems development, nor does it have a tradition of model-theoretic approaches which are familiar in information systems research to describe and predict problems and their solutions. If we are to implement ERP solutions which recognise corporate and national cultures, we need at least to model culture to describe and to predict its impact on an ERP implementation. This is the focus of a current research programme based in the Centre for HCI Design and supported by the world's largest ERP vendor SAP. This paper reports first results from the programme.

The model of culture presented in this paper synthesises social and system science theories of corporate [e.g. 20] and national [e.g. 21] culture. A method then applies the resulting model to design and evaluate methods for adapting ERP implementations to fit the corporate culture. It assumes that the customer's national culture is manifest through the corporate culture. As shown in Figure 1, current ERP package implementations reveal 3 types of culture-related problem which impact on a successful implementation: (i) the current corporate culture clashes with the planned future culture; (ii) the supplier's culture, implicit in the ERP package, clashes with the customer's corporate culture, and; (iii) the new business processes (configured using the ERP solution) clashes with the existing corporate culture. All of these types of clash necessitate customisation of the business processes and software to resolve the clash. However, such customisation is expensive: on average 10-20\% of an ERP implementation budget is spent on ERP customisation (source: Forrester Research).

Our research posits that to detect these 3 types of culture-related clash we need to be able to model: (i) the customer's business processes and solution systems; (ii) facets of the corporate and national culture which impact on the implementation of 


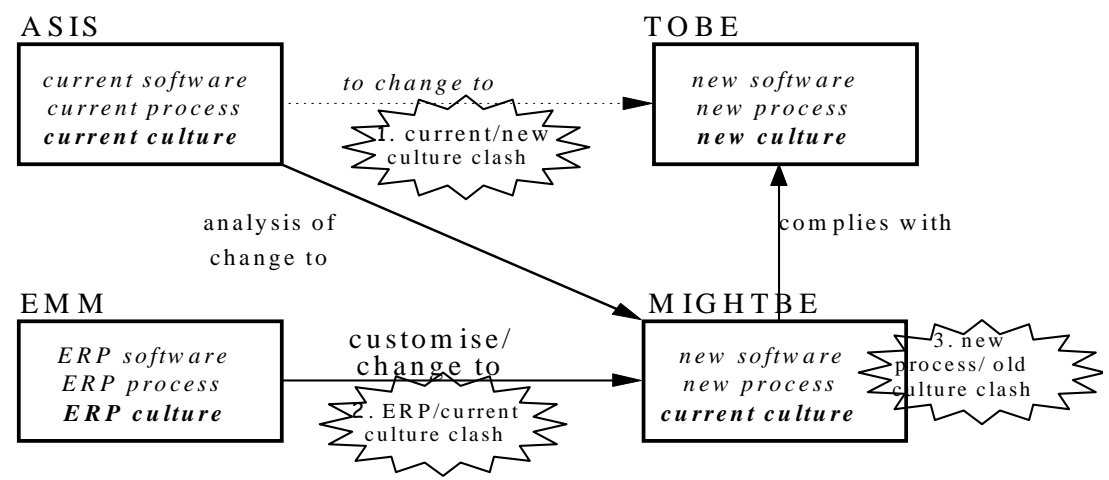

Fig. 1: How culture impacts on ERP implementation. During an ideal ERP implementation process there will be 4 different models of the organisation's culture, processes and software systems: (i) the ASIS model, which describes the organisation's current culture, processes and software; (ii) the TOBE model, which describes the required culture, processes and software; (iii) the ERP model, which describes the ERP supplier's processes, software and culture; (iv) the MIGHTBE model, which describes how future processes and software will operate in the current culture.

these business processes; (iii) how these facets of corporate and national culture impact on the business and software solutions. The research also posits a method to exploit these models during ERP implementation. The implementation team will use current ERP modelling approaches to model the current and future business processes. It will then extend these models with features of corporate and national culture. The team will discover potential problems by analysing the differences between the two business process models using predictions of possible problems using theories of corporate and national culture. The method will also deliver advice to the implementation team to resolve these problems through a set of Culture Impact Patterns. The outline method is shown in Figure 2. This paper reports research into the first stage of the method, to model the essential characteristics of corporate culture which impact on ERP package implementation.

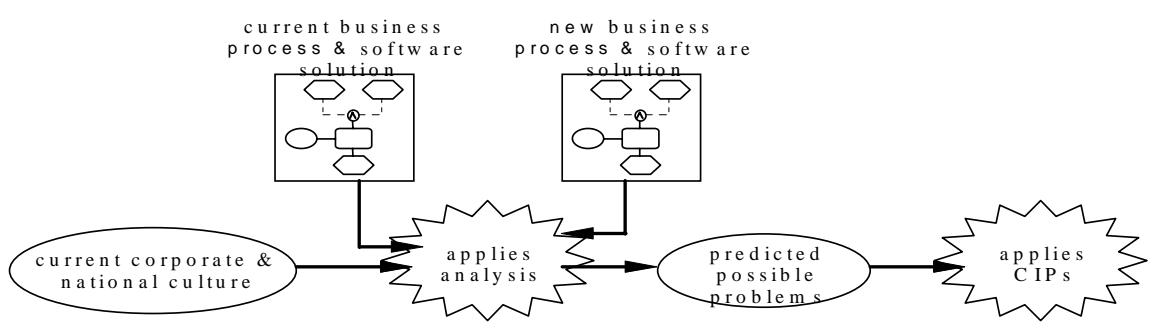

Fig. 2: An outline of the extended ERP implementation method for culture-sensitive ERP implementation. 
The remainder of this paper is in 5 sections. Section 2 summarises existing social science theories of culture. Section 3 presents the first-draft model of culture. Section 4 describes the results from studies of the impact of culture of an ERP implementation on a UK customer. Section 5 outlines cultural impact patterns, their link to the model and how implementation teams might use them. The paper ends with a brief discussion and presentation of future research.

\section{Social Science Research on Corporate and National Culture}

Most social science research on culture can be divided into two camps [8]. The first camp claims that culture is something tacit which arises naturally. The other, more common view is that culture is something explicit, which arises from social interaction. Social science research also divides research into culture into research into national cultures, business cultures and corporate cultures. A good starting point is Schein (1992) who provides the following definition of corporate culture:

"a pattern of basic assumptions - invented, discovered or developed by a given group as it learns to cope with its problems of external adaptation and internal integration - that has worked well enough to be considered valid and therefore to be taught to new members as the correct way to perceive, think and feel in relation to those problems".

He argues that corporate culture can be divided into three layers. In the outer layer there are values which are written down statements about the strategies, missions and objectives of the organisation. In the middle layer there are beliefs which are the issues that the employees of an organisation talk about. In the inner layer there are the "taken for granted" assumptions which are those aspects of the organisational life which people find it difficult to recall and explain. Schein also describes 10 dimensions that he uses to differentiate between corporate cultures in different organisations. These are the observed behavioural regularities of human interaction; the group norms; the espoused corporate values; the formal philosophy; the rules of the game; the climate; the habits of thinking; people's mental models and/or linguistic paradigms; their shared meanings; their embedded skills; and the organisation's root metaphors' or integration symbols. These dimensions indicate important classes and attributes of culture to model in order to understand its impact on ERP implementation.

Hofstede (1994) also investigated corporate and national culture. He argues that there are 4 manifestations of culture, and the differences between national and corporate culture are due to their different uses. These manifestations are also placed in layers similar to the layers from Schein (1992). Hofstede differentiates between layers that have symbols which represent the most superficial culture often described as practice, layers which have values which represent the deepest manifestations of culture, and intermediate layers which describe heroes and rituals indicative of the corporate culture. He claims that national culture differences reside more in values and less in practices, and organisational culture differences reside more in practices 
and less in values. Furthermore, he claims that we can detect national and corporate culture differences using a set of dimensions similar to those from Schein (1992). From extensive empirical studies Hofstede provides 4 dimensions, which differentiate between national cultures: power distance, individualism-collectivism, masculinityfemininity, and uncertainty avoidance [11]. Likewise, he detects 6 dimensions to differentiate between organisational cultures: process- versus results-oriented; employee- versus job-oriented; parochial- versus professional-dependent; open versus closed systems of communication; loose versus tight control; and normative versus pragmatic organisations [11]. As with Schein's findings, Hofstede's dimensions indicate important elements of culture which we need to model in order to understand the impact on ERP implementation.

Trompenaars (1994) argues that national culture can be described with 3 layers similar to those from Hofstede. A central theme of Trompenaar's argument is that people organise themselves in such a way so as to increase the effectiveness of their problem-solving processes, and so have formed different sets of implicit logical assumptions to enable this to happen. Each culture distinguishes itself from others in terms of its solutions to these problems. These problems can also be classified to differentiate between national cultures in a similar way to which Hofstede uses his 6 dimensions. These classes are how people relate to each other (sub-divided into universalism versus particularism, individualism versus collectivism, neutral versus emotional, specific versus diffuse, achievement versus ascription), people's attitudes to time, and people's attitudes to the environment [21]. Again, these classes provide a basis for modelling the critical determinants of corporate and national cultures.

Our extensive research of the key social sciences research into culture summarised here reveals 4 conclusions, which we might be able to exploit to improve ERP implementation:

- theories of corporate and national culture have similar definitions of culture and share important concepts which include values, beliefs and norms;

- these theories distinguish between the deep manifestations and the superficial features of corporate and of national culture;

- critical determinants of a corporate culture reside more in observable practices, whereas critical determinants of a national culture reside more in the nation's deeper set of values;

- corporate and national culture can be described using multiple dimensions which give us a set of overlapping facets with which to describe aspects of culture.

Our wider research programme uses these conclusions to posit 4 key research hypotheses which drive the programme. First, it posits that corporate and national culture has a direct impact on ERP implementation problems which customer organisations experience during implementation. Second, it posits that social science theories can describe the problems observed in current ERP implementations. Third, it posits that a synthesis of social science theories of culture can be applied to explain culture-related problems which arise during ERP implementations. Fourth, the programme posits that these theories can be applied to predict such problems in future ERP implementations. In the next section we report research which explores the first and second hypotheses. We apply social science research to develop a first-draft 
model of corporate and national culture which can be applied to describe culturerelated problems during ERP implementations. It is the main focus of this paper.

\section{A Model of Culture for ERP Implementation}

The enhanced ERP implementation method outlined in section 1 integrates current business processes approaches with models of corporate and national culture to discover potential problems using predictions of possible problems using social science theories of corporate and national culture. The basis of the model is a knowledge meta-schema for modelling the critical elements of corporate and national culture. This, in itself, is an innovative advance. Social science does not have a tradition of conceptual modelling to describe and analyse systems. Indeed, noncomputer science disciplines resist conceptual modelling because it is too difficult to capture and describe the knowledge without losing the essential context of the knowledge. However, the common definitions of culture from social science researchers offer exciting opportunities. We have synthesised and extended these social science theories to model the problems observed in current ERP implementations.

The first stage of the research was to design a knowledge meta-schema capable of representing both the deeper manifestations and the superficial attributes of corporate and national culture, and the critical causal associations between them. The knowledge meta-schema also integrates these attributes with standard business process models such as SAP's EPC models so that the knowledge meta-schema can be used in methods such as SAP's ASAP method. For readers unfamiliar with these models, a segment of an EPC model for invoice processing taken from version 4.5 of SAP's R/3 includes events, processes and event flows for business processes. The full first-draft knowledge meta-schema is shown in Figure 3 below.

Space does not allow us to give a full definition of the knowledge meta-schema. Instead we provide key definitions drawn first of all from software and business process models common in current ERP implementation methods such as ASAP. An agent is a type of object, which processes actions [18]. Agents perform actions to achieve goals. With respect to culture, agents have beliefs, values and norms that govern their actions. One instance of an agent can be one individual person, a collection of people, one machine or a collection of machines. An action is the process of doing something with the intention of achieving a desired goal [17]. Actions are constrained by pre-conditions and post-conditions. Pre- \& postconditions are conditions which must occur for an action to begin or end. An event is a moment in time when something happens. In the knowledge meta-schema events start and end actions. An object is something which is manipulated for the attainment of a goal. An object can be a physical object (e.g. a radio), an infological object (e.g. information about an incident) or an object with both physical and infological elements (e.g. an incident report). A goal is a high-level objective that the system should meet. Goals are achieved by actions performed by agents manipulating objects [5]. These concepts are common in most current ERP business modelling approaches 


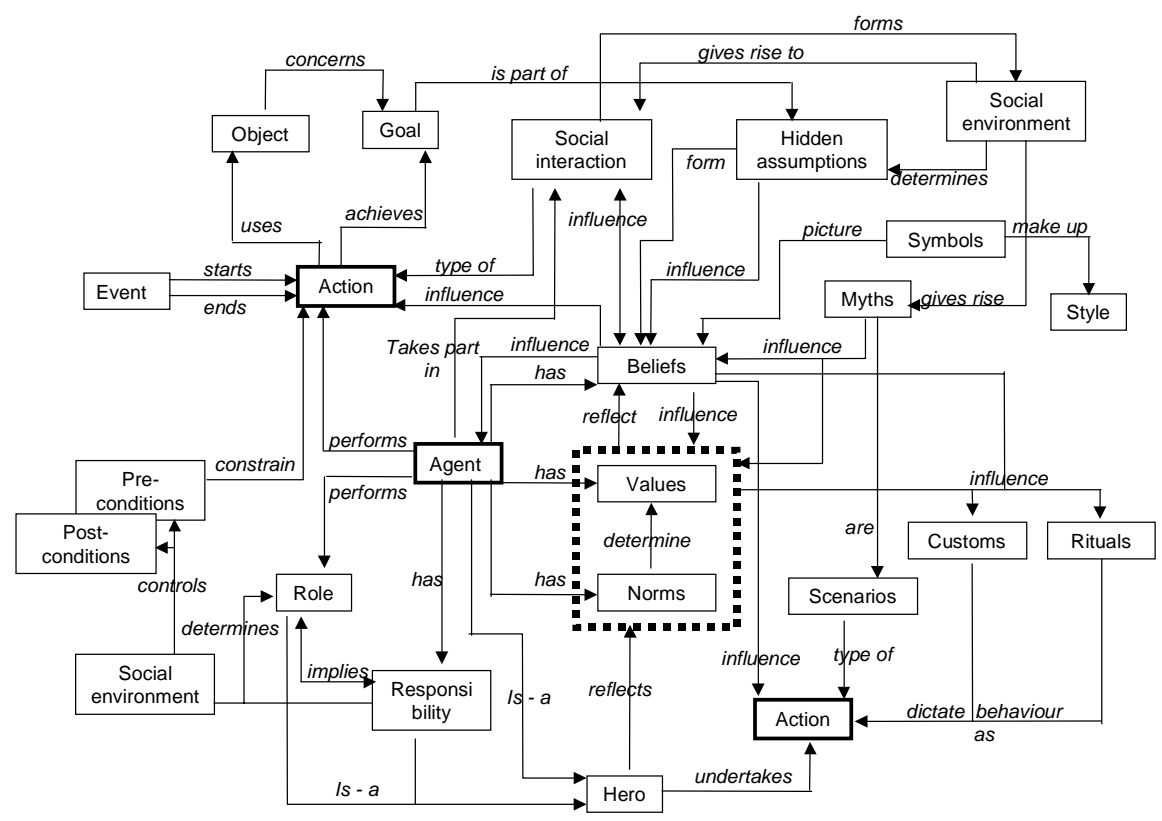

Fig. 3: The knowledge meta-schema that describes elements of corporate and culture, which impact on ERP implementation

and represent many of the more observable indicators of corporate culture according to Hofstede (1994).

The rest of the knowledge meta-schema is drawn from social science research into culture which is summarised in the previous section. All are critical determinants of corporate and national culture according to the theories reported in the previous section. A role defines the obligations of an agent. An agent can fulfil one or more role types. Responsibilities define the liabilities of the agents associated with the role they perform. Agents are responsible for fulfilling a role and initiating, controlling or undertaking actions related to their role [17]. A hero is a human agent admired by other agents in the organisation [6]. Heroes are agents that, through their role and responsibilities, undertake actions which reflect the organisational beliefs, norms and values. A social interaction describes an interaction between agents. It is a specialisation of an action. Social interaction can influence agents and their beliefs. A belief is an agent's feeling that something is true, or good or exists [11,20]. Beliefs influence agents and their actions, values and norms, and the customs and rituals adopted within an organisation [8]. Each belief is influenced and formed by hidden assumptions. A value is a standard, a principle or an ideal about the worth or importance of something. Each value can exist on spectrums such as good versus evil and normal versus abnormal [11,20]. Each value also reflects a belief and so influences agents and their actions. A norm is a standard expectation of what is normal and what is right or wrong [11,21]. A norm influences values which reflect beliefs and, in turn, influence agents and actions. 
A hidden assumption is an implicit assumption about the rationale for something. It reveals important information about the source and the nature of business processes and the organisation which, in turn, form the organisational beliefs [21]. A scenario is a sequence of events which start and end actions, which describe current or future business processes and/or ERP software use [17]. Scenarios can describe norms, and can be embellished with contextual information to create stories. A myth is a scenario, either factual or invented, which encapsulates the organisation's and/or agent's beliefs, norms and values [12]. A custom is an established behaviour expressed as actions, codes or rules of behaviour [6]. Customs are created and influenced by norms, values and beliefs, and influence behaviour in the form of actions and events. A ritual is a repeated action or scenario that express the goals and values of the organisation and dictate behaviour in the form of actions $[11,6]$. Symbols are objects explicit to people outside the organisation such as buildings and logos which are manifestations of the organisation's hidden assumptions, beliefs, norms and values [11]. Finally, the style is the way people are dealing with other people within an organisation, such as the way they talk to each other. Symbols form the style of the organisation [19].

The knowledge meta-schema defines the elements which define corporate and national culture and the critical associations between them needed to link the surface and deeper manifestation of the culture. The next section reports initial findings to validate the knowledge meta-schema's effectiveness for describing these critical elements of culture which influence ERP implementations.

\section{Validating the Knowledge Meta-schema: The Impact of Culture on an ERP Implementation}

In order to validate whether the knowledge meta-schema can describe critical elements of culture, we undertook field studies in an UK higher education establishment whose finance department had recently implemented SAP's R/3. We undertook two interviews each with three different stakeholders of the implementation ERP package. In the first interview, each stakeholder was asked to describe his/her job, department, background information and problems which had arisen due to the implementation. In the second interview, the stakeholders were asked questions to elicit evidence about the corporate culture of the institution. A prepared set of questions were asked to elicit underlying causes, including possible cultural causes, for those problems mentioned in the first interview. The questioning method was derived from a synthesis of culture dimensions undertaken by the authors based on dimensions from Hofstede, Schein and Trompenaars reported in section 2 . These dimensions enable us to describe and compare critical manifestations of corporate and national culture. The application of a "neutral" method from social science research counters claims that the studies "found what they were looking for" in terms of the posited knowledge meta-schema. 
1. How long have you been working in the department?

2. What is your position in the organisation?

3. How well do you believe you understand the culture of the university and department?

4. Do you have any contact with other departments?

5. Do you believe that you fit to the university or the departmental culture?

6. If then how have your roles and responsibilities changed as a result of the new system?

7. Were partner consultants involved with you during the new system implementation?

8. How has your work changed as a result of the new system?

9. What problems have arisen as a result of the new system?

10. Have these problems impacted on how work is done? How?

11. Have there been any security implications from these problems?

12. Do you and your colleagues talk about these problems?

13. What do you see as the source of these problems and why?

14. Have problems arisen from poor implementation of the new system?

15. Have these problems been supported by high-level management?

16. Were you happier with the old system?

17. What was your first impression of the new system, and has it changed?

18. Have problems experienced by you and your colleagues led to stress?

19. How would you characterise the general climate prevailing in the department now after the ERP implementation?

Fig. 4: Questions asked during the first interview.

\subsection{The First Interviews}

The first interview elicited information about stakeholders, the corporate culture, the ERP implementation and the problems or issues that it created. The interviewer asked open-ended questions followed by more specific ones to elicit reasons and rationale about the culture and the ERP implementation-related problems. This provided data about how the current system, the ERP implementation, problems which arose during the implementation and the climate resulting from the implementation. A sample set of questions is shown in Figure 4. All interviewees responded to these questions.

\subsection{The Second Interviews}

The purpose of the second interview was to elicit surface manifestations of corporate culture, then use a variation of the laddering technique from knowledge engineering [16] to elicit deeper determinants of culture which were possible causes of these surface manifestations and problems reported in the first interview. The elements of culture found on outer layers of the social science models are the observable manifestations of culture. Elements of culture found in the inner layer are tacit, more important determinants of national and, to a lesser degree, corporate culture. Our questions were designed to elicit the observable manifestations of culture described on the outer layers then use precise verbal probes to elicit tacit rationale for these manifestations. This use of external manifestations of culture to elicit deeper underlying causes was the principal reason for two interviews rather than one. The 


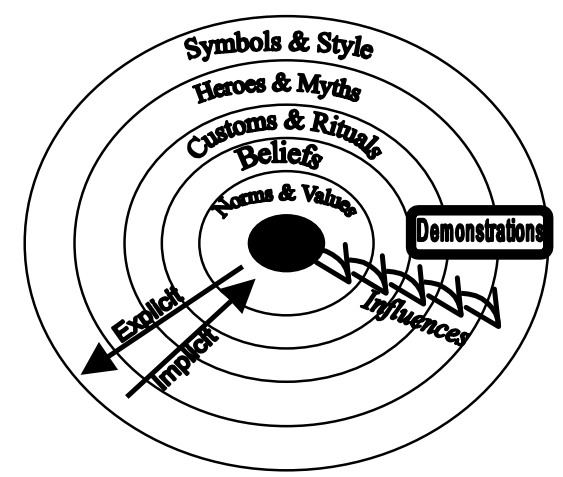

Fig. 5: a synthesis of the layers of the elements of culture taken from social science research to provide a basis for the questioning method.

specific questioning approach was based on a synthesis of these layers of culture from social science research which is shown in Figure 5. Questions asked to elicit the external manifestations of the culture included: Is management more concerned with getting work done than with the people who do the work, Is good work rewarded, and Are there "rules" that a newcomer must learn to be accepted in the department? The laddering technique was then applied to "drill down" through the layers of culture shown in Figure 5 through repeated asking of "why?" and "how?" questions.

All interview data was analysed to determine key culture-related phenomena relevant to the ERP implementation. Relevant segments were transcribed and analysed by the authors. Each of these segments was then analysed further to determine critical elements of culture and causal associations between them using the knowledge meta-schema definitions outlined in section 3 and detailed questions asked in the second interview.

\subsection{Preliminary Results}

Results from the first interview reveal that most ERP implementation problems were related to procedures, workloads and the lack of training made available to the endusers of the new system. The interviewees offered numerous opinions about why this was. Reasons included the lack of access to official training courses and the time to go on the training courses. This data provided the basis for the second interviews. The results from the second interviews were more complex. We are still completing a full analysis of the data to determine the degree of fit between the elicited data and the posited knowledge meta-schema. This paper samples this data, and presents 3 result segments which demonstrate the detected patterns of the results so far.

The first transcript segment reveals the problem of an uneven allocation of extra work resulting from the implementation of the ERP system. The accounts services manager believed that his work would be easier and more fun because of the implementation of $\mathrm{R} / 3$. He believed that he would learn a new system and make his work better and more efficient. However, after implementation, work such as 


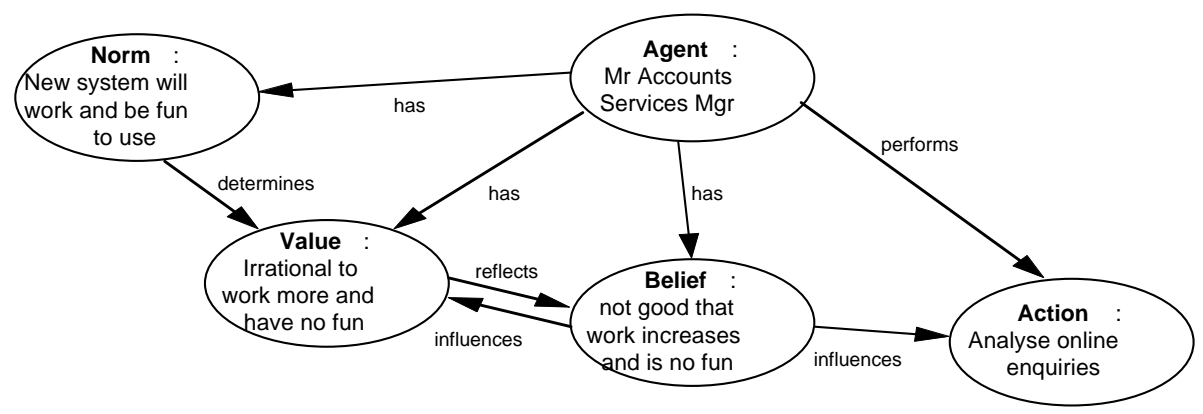

Fig. 6: a partial instantiation of the knowledge meta-schema using data from the second interview with the accounts services manager.

analysing online enquiries increased and became more complex, which he believed was irrational. The increased work had a direct effect on his satisfaction and motivation to complete the work, which led to more mistakes. The definitions of culture were applied to the transcript data to determine elements of culture, and then a simple model was developed. This instantiation of the knowledge meta-schema to model the elements of culture identifiable from the data is shown in Figure 6.

The application of the knowledge meta-schema identifies the importance of the agent's norms, values and beliefs on problems arising from a process (shown as an action in the meta-schema). The critical element of this model is the violation of the agent's expectation expressed as a norm, which in turn reflects the agent's beliefs which influences the agent's behaviour in the process. This model-driven analysis of the problem is a richer explanation of the observed problem than just saying that the agent's increased workload impacts on the analysis of online enquiries. Indeed, the identification of an important agent norm enables us to explain and predict other possible problems with other processes undertaken by the same agent or similar agents if the norm does not occur. In short, the use of the knowledge meta-schema enables us to identify, describe and model more fundamental drivers which influence ERP implementations.

In another transcript segment, the accounts assistant believed that the implementation and training on the new system that he would receive would enable him to do his work faster and more accurately. However, he believed that the training received on the new system was inadequate. This individual valued high-quality training to use such a new system successfully. Instead the lack of training increased the number of mistakes and he believed that he was unable to perform his roles and responsibilities effectively. This was also a view held by other colleagues in the department. Again the definitions of culture were applied to the transcript data to determine elements of culture, and a simple model which instantiates the knowledge meta-schema was developed. This model is shown in Figure 7.

Again the knowledge meta-schema highlights the influence of the agent's norms, values and beliefs on a process. The accounts assistant values training and expects training to be available for the new system, but he believes that the insufficient training influe nces performances of processes such as issuing invoices. Again the 


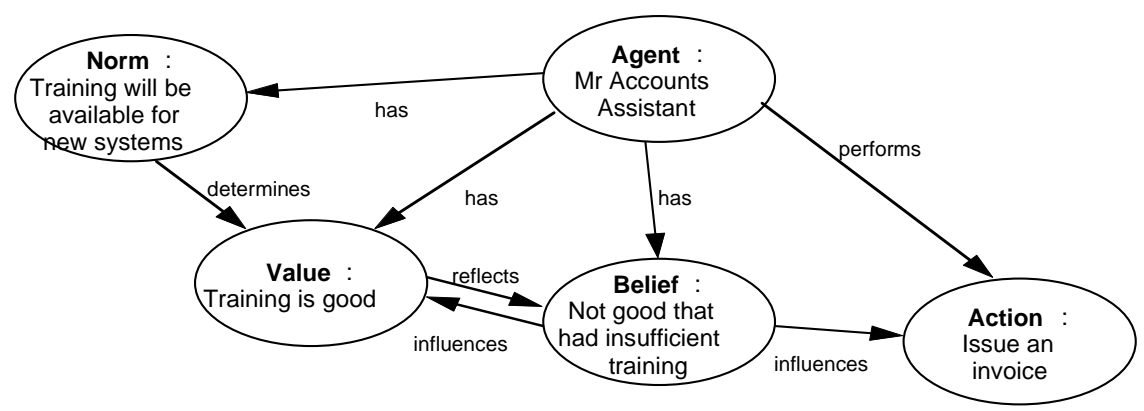

Fig. 7: a partial instantiation of the knowledge meta-schema using data from the second interview with the accounts assistant.

critical element of this model is the violation of the agent's expectation expressed as a norm (training will be available) which in turn reflects the agent's beliefs which influences the agent's behaviour in the process. As with the first model, this modeldriven analysis provides us with a richer explanation of the observed problem than a simple statement of inadequate training. Indeed, the identification of an important agent norm again enables us to explain and predict other possible problems with other processes undertaken by the same agent or similar agents if the norm does not occur.

In a third transcript segment the accounts payable manager believed that staff levels should match the new work levels across the department. However, the introduction of the new system meant that he had to import information from the old system into the new system on top of his other work activities, whereas other sections in the department received extra staff to manage the implementation of the new system. The accounts payable manager felt that this was unfair. His increased workload led to less interest, less motivation and more mistakes. The model derived from this segment of transcript data is shown in Figure 8.

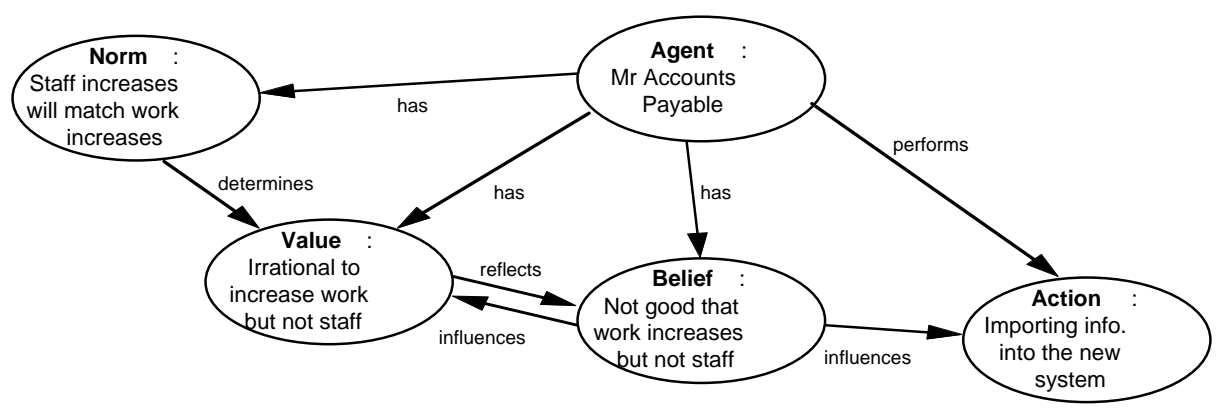

Fig. 8: a partial instantiation of the knowledge meta-schema using data from the second interview with the accounts payable manager.

This model reveals an emerging pattern in agent's norms, values and beliefs relevant to this ERP implementation. The accounts payable manager expected staff levels to match work levels resulting from the new system, and believes that it is not 
good if this does not happen which in turn influenced his performance on business processes. The critical element of the model is the violation of the agent's norm which determines values and beliefs which influence his actions. Again the modeldriven analysis provides us with a richer explanation of the observed problem. The identification of another important agent norm again enables us to explain and predict other possible problems with other processes undertaken by the same agent or similar agents if the norm does not occur.

\subsection{Preliminary Conclusions}

Preliminary evidence from the studies reported here and elsewhere reveals 5 conclusions regarding the impact of the corporate culture on ERP implementation:

- social science techniques are effective for eliciting culture-related data about ERP implementations, albeit after the implementation has taken place;

- the posited knowledge meta-schema can be applied to model this data;

- the application of the knowledge meta-schema introduces more precision to the description of ERP implementation problems;

- the knowledge meta-schema can be applied to model critical elements of culture which influence implementation problems: in the 3 models shown the meta-schema was applied to link the violation of an agent's norm or expectation to observable problems linked to business processes;

- these implementation problems are modelled as complex patterns of knowledge about agents, norms, values, beliefs and actions, as shown in Figures 6, 7 and 8.

The posited ERP implementation method will only be effective it offers consultants and customers sufficient leverage over the implementation problems. The main benefit of the knowledge meta-schema shown in these preliminary results is that the meta-schema enables us to model more important but deeper influences which can influence all business processes which agents are involved in. The final section explores one solution for exploiting this leverage which builds on the fifth conclusion, that implementation problems are modelled as complex patterns of knowledge about agents, norms, values, beliefs and actions.

\section{Delivering Benefits: Cultural Impact Patterns}

One criticism of existing management science theories of culture is their lack of application to improve organisational change. We aim to deliver this application through patterns which describe culture-related impacts. A pattern is an abstraction of a problem, a solution to the problem AND the context(s) in which this solution is applicable [9]. Patterns have come to IT design from architectural design. Alexander (1977) posits that pattern languages are collections of patterns used by a process to generate artefacts that are complexes of patterns. 
Pattern detection and application necessitates a more formal expression of the problem in context. This is where the knowledge meta-schema comes in. The models which instantiate the knowledge meta-schema, shown in Figures 6, 7 and 8, enable us to model this problem and context so that solutions to improve ERP implementations can be applied to the right problem at the right time. However, the successful identification and application of these patterns remains research conjecture which we will examine later in the research programme.

\section{Conclusions and Future Work}

This paper reports the results of preliminary research into the implementation of ERP packages in organisations with diverse corporate and national cultures. It exploits social science theories [11,21] to posit a model of corporate and national culture characteristics, which, we hypothesise, impact on ERP implementations. It describes a knowledge meta-schema with which to model these characteristics. Postimplementation studies of an ERP implementation in a higher education institution were undertaken to provide data to validate the knowledge meta-schema's power of description. Preliminary findings are positive: the knowledge meta-schema was applied to detect the importance of deviations from agent's expected norms which influence how the agent undertakes business processes. The elicitations of these cultural norms are an example of how the identification of the deeper cultural characteristics can offer greater leverage to customers and consultants during ERP implementation. The results provide the foundation for accepting the first and second research hypotheses of this research programme stated in the final paragraph of section 2 .

However, the data reported here only provide weak validation of parts of the knowledge meta-schema and no validation at all of social science theories to explain and predict the impact of different corporate and national cultures on ERP implementations. Instead the reported scientific results raise our awareness of the potential importance of culture on ERP implementation only hinted at anecdotally so far in Gulla \& Mollan (1999) and Densley (1999). The paper also advocates the possible use of patterns to detect and resolve common, recurring problems during ERP implementations. To provide more complete validation the authors are currently undertaking on-site studies of the implementation of several ERP packages in the same organisations across Europe. Data elicited from these studies will provide more extensive validation of the knowledge meta-schema and, more importantly, predictions from social science theories which will deliver real benefits to the proposed ERP implementation method. We look forward to reporting these more complete results when they are available. 


\section{References}

1. Alexander C., 1977, 'A Pattern Language', Oxford University Press.

2. Anton A. \& Potts C., 1998, 'The Use of Goals to Surface Requirements for Evolving Systems', Proceedings 19th IEEE International Conference on Software Engineering, IEEE Computer Society Press.

3. Cartwright S. \& Cooper G.L., 1996, 'Managing Mergers, Acquisitions and Strategic Alliances: Integrating people and cultures', Butterworth-Heinemann Oxford.

4. Curran T.A. \& Ladd A., 1999, 'SAP R/3 Business Blueprint', Prentice-Hall.

5. Darimont .R \& Van Lamsweerde A., 199*, 'Formal Refinement Patterns for Goal-Driven Requirements Elaboration', Proceedings $4^{\text {th }}$ ACM Symposium Foundations of Software Engineering, ACM Press, 179-190.

6. Deal T. \& Kennedy A., 1982, 'Corporate Cultures: The Rites and Rituals of Corporate Life', Penguin Books, London.

7. Densley B., 1999, 'The Magnificent Seven: Getting the Biggest Bang from the ERP Buck', Proceedings 1st Intl Workshop EMRPS99, eds J. Eder, N. Maiden \& M. Missikoff, Istituto de Analisi dei Sistemi ed Informatica, CNR Roma, 59-65.

8. Dobson P., Williams A., \& Walters M., 1993, 'Changing Culture: New Organisational Approaches', Institute of Personnel Management, London, 2nd edition.

9. Gabriel R., 1995, 'Patterns of Software', Oxford University Press.

10. Gulla J.A. \& Mollan R., 1999, 'Implementing SAP R/3 in a Multi-Cultural Organisation', Proceedings 1st Intl Workshop EMRPS99, eds J. Eder, N. Maiden \& M. Missikoff, Istituto de Analisi dei Sistemi ed Informatica, CNR Roma, 127-134.

11. Hofstede G., 1990 \& 1994, 'Cultures and Organisations', Intercultural Co-operation and Its Importance for Survival. Software of the Mind, Author of Culture's Consequences, Harper Collins, London.

12. Johnson G., 1992, 'Managing Strategic Change: Strategy, Culture and Action', Long Range Publishing 25(1), pp??

13. Johnson G. \& Scholes K., 1997, 'Exploring Corporate Strategy: Text and Cases', Prentice Hall Europe.

14. Kotter J.P. \& Heskett J.L., 1992, 'Corporate Culture and Performance', The Free Press, New York USA.

15. Maiden N. A. M., Minocha S. \& Manning K., 1996, 'Socio-Technical System Scenarios: A Template based Approach', Technical Report, Centre for HCI Design, City University, London.

16. Maiden N.A.M. \& Rugg G., 1996, 'ACRE: A Framework for Acquiring Requirements', Software Engineering Journal 11(1).

17. Maiden N.A.M, 1998, 'SAVRE: Scenarios for Acquiring \& Validating Requirements', Journal of Automated software Engineering 5, 419-446

18. Ncube c. \& Maiden N.A.M., 1999, 'Guidance for Parallel Requirements Acquisition and COTS Software Selection', Proceedings $4^{\text {th }}$ IEEE Symposium on Requirements Engineering, IEEE Computer Society press, xx-xx

19. Peters \& Waterman, 1982, 'In Search of Excellence”, Harper \& Raw, New York.

20. Schein E. H., 1992, 'Organisational Culture and Leadership', Jossey-Bass Publishers, San Francisco.

21. Trompenaars F., 1994, 'Riding the Waves of Culture: Understanding Cultural Diversity in Business', Nicholas Brealey Publishing, London.

22. Vernon M., 1999, 'ERP endangered species?', Computer Weekly, 4/11/99 p.32 